\title{
Algunas consideraciones sobre el Centro Naval durante la Primera
} Guerra mundial 1914-1918

\author{
Some considerations on the Naval Centre during the First World \\ War 1914-1918
}

\author{
AGUSTÍN DANIEL DESIDERATO \\ Consejo Nacional de Investigaciones Científicas y Técnicas - Instituto \\ de Historia Argentina y Americana "Dr. Emilio Ravignani” - Grupo \\ de Estudios Históricos sobre la Guerra / Escuela Superior de Guerra - \\ Facultad del Ejército - Universidad de la Defensa Nacional (CONICET- \\ IHAYA-GEHiGue / ESG-FE-UNDEF) \\ addeside@gmail.com
}

Resumen: Las investigaciones sobre las repercusiones de la Primera Guerra Mundial en la República Argentina han sido dinámicas en los últimos tiempos, más allá de la neutralidad del país y de su distanciamiento de los principales frentes de batalla. No obstante, algunas cuestiones todavía permanecen mayormente desatendidas. Una de ellas es cómo y de qué forma la contienda impactó en las Fuerzas Armadas, en especial, en el funcionamiento de los clubes y centros militares. Para ello se tomará el caso del Centro Naval, institución que reunía a la mayor parte de la oficialidad de la Armada Argentina, entre 1914 y 1918, mediante el análisis de dos cuestiones: primero, su actividad social, a saber, los encuentros, reuniones y visitas que tuvieron lugar en sus instalaciones; segundo, la composición y el tipo de contenido que emitió su principal publicación, el Boletín del Centro Naval.

Palabras clave: Primera Guerra Mundial, Centro Naval, Armada Argentina, oficiales, publicaciones militares.

Abstract: The research on the repercussions of the First World War on the Argentine
Republic has been dynamic in recent times, beyond the country's neutrality and its
distance from the main front lines. However, some issues remain largely neglected. One
of these is how and in what way the conflict has impacted on the Armed Forces, especially
on the functioning of military clubs and installations. For this purpose, the case of the
Centro Naval (Naval Centre), an institution that brought together most of the officers of
the Argentine Navy between 1914 and 1918, will be examined by analyzing two issues:
first, its social activity, that is, the meetings, reunions and visits that took place in its

Recibido: 15 de febrero de 2021; aceptado:18 de mayo de 2021; publicado: 30 de septiembre de 2021.

Revista Historia Autónoma, 19 (2021), pp. 169-183

e-ISSN: 2254-8726; https://doi.org/10.15366/rha2021.19.009 
facilities; second, the composition and the kind of content issued by its main publication, the Boletín del Centro Naval (Naval Centre's Bulletin).

Keywords: First World War, Naval Centre, Argentine Navy, officers, military publications.

\section{Introducción}

El Centro Naval fue fundado en la Ciudad de Buenos Aires, el 4 de mayo de 1882, como una sociedad compuesta por miembros de las distintas reparticiones de la Armada Argentina, aunque sin un vínculo oficial con ella ni con ninguna otra esfera de competencia estatal. Sus objetivos fueron varios: primero, "promover y fomentar la unión, instrucción y espíritu de todos sus miembros" e inspirar en el país y el exterior una opinión favorable a la Armada, efectuando trabajos que denoten la competencia de sus cuadros; segundo, ofrecer a los oficiales extranjeros un punto de reunión, donde puedan estrechar relaciones con sus pares argentinos; por último, presentar proyectos a las autoridades de gobierno, sobre las necesidades y progresos de la Marina, creando y manteniendo una revista o boletín, donde los socios pudieran publicar sus trabajos ${ }^{1}$.

Durante sus primeros años, el Centro Naval no contó con una sede social estable. El edificio definitivo empezó a construirse en 1911, en la Ciudad de Buenos Aires (calle Florida 801), por obra de los arquitectos franceses Gastón Mallet y Jacques Dunant y se inauguró en $1914^{2}$. Desde entonces, fue sede de visitas, reuniones y encuentros, a los que solían asistir representantes diplomáticos, políticos y militares, tanto de la órbita nacional como internacional ${ }^{3}$. Asimismo, se celebraban diversas actividades, desde concursos y certámenes hasta conferencias magistrales, en las que algunos oficiales, tanto argentinos como extranjeros, impartían conocimientos sobre temas de su competencia ${ }^{4}$. Esta actividad se difundía en las páginas del Boletín del Centro Naval, junto a noticias y artículos especializados, para mantener "siempre al corriente" a los lectores y socios de "todos los progresos y adelantos" relacionados "con las innovaciones modernas en el arte de la guerra marítima".

Como punto de reunión y sociabilidad con más de un siglo de existencia, el Centro Naval fue (y es) sumamente importante en el seno de la Armada Argentina. No obstante, los

\footnotetext{
${ }^{1}$ Estas razones fueron establecidas por el artículo $1^{\circ}$ de su reglamento (“Objeto de la sociedad”, en Boletín del Centro Naval, 1 (1884), p. 5).

${ }^{2}$ González Lonzieme, Enrique, Historia del Centro Naval en su centenario, Buenos Aires, Instituto de Publicaciones Navales, 1983, p. 137; “Centro Naval”, en Caras y Caretas, 9 de mayo de 1914.

${ }^{3}$ Rojas Torres, Daniel, "Memoria Anual de la Comisión Directiva del Centro Naval 1913-1914", en Boletín del Centro Naval, 364/365 (1914), p. 54.

${ }^{4}$ Ibidem, p. 57.

${ }^{5}$ Albarracín, Santiago J., “Algunas palabras”, en Boletín del Centro Naval, 1 (1884), p. 8.
} 
círculos académicos han manifestado poco interés en él, más allá de su importancia como escenario de ciertos hechos relacionados con la formación de la agrupación nacionalista Liga Patriótica Argentina ${ }^{6}$. Fuera de ello, los trabajos son reducidos y se limitan a abordajes de índole institucional, con una narrativa que describe las transformaciones y continuidades del Centro Naval a lo largo del tiempo, pero sin alcanzar preguntas de investigación más complejas, que lo puedan insertar en un marco más amplio ${ }^{7}$. Por ejemplo, ¿cómo se relacionó con la Primera Guerra Mundial, un evento de alcance total y global ${ }^{8}$ Esta es la primera pregunta que nos hacemos.

La República Argentina mantuvo su neutralidad durante todo el conflicto, aunque no estuvo exenta de experimentar importantes efectos económicos, políticos, sociales y diplomáticos. Estos asuntos han sido fruto de una extensa producción académica, que mantiene su dinamismo hasta el presente ${ }^{9}$. Sin embargo, no ocurrió lo mismo con las repercusiones de

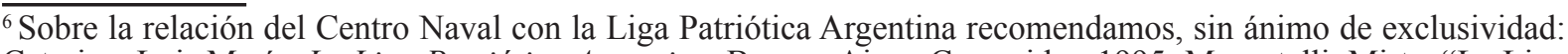
Caterina, Luis María, La Liga Patriótica Argentina, Buenos Aires, Corregidor, 1995; Moscatelli, Mirta, "La Liga Patriótica Argentina. Una propuesta nacionalista frente a la conflictividad social de la década de 1920 ", en $L a$ Trama de la Comunicación, 7 (2000), pp. 197-204. «https://rephip.unr.edu.ar/handle/2133/741» [consultado el 27 de enero de 2021]; Girbal-Blacha, Noemí María, "La Liga Patriótica Argentina en el Congreso Nacional (19191960). La pervivencia del poder político entre bastidores", en La Rivada, 6, 10 (2018), pp. 139-151. https://doi. org/10.35305/ese.v6i12.231

${ }^{7}$ Para una bibliografía sobre el Centro Naval, ver: González Lonzieme, Enrique, Historia del Centro Naval... op. cit.; Rodríguez, Horacio y Jorge Bergallo, Centro Naval: unión y trabajo, Buenos Aires, Instituto de Publicaciones Navales, 2005.

${ }^{8}$ Sobre el carácter total de la Gran Guerra, ver: Horne, John, "Introduction: mobilizing for total war, 19141918", en Horne, John (ed.), State, Society, and mobilization in Europe during the First World War, Cambridge, Cambridge University Press, 1997, pp. 1-18. https://doi.org/10.1017/CBO9780511562891.002; Becker, Annette, "The Great War: World war, total war", en International Review of the Red Cross, 97, 900 (2015), pp. 10291045. https://doi.org/10.1017/S1816383116000382; El aspecto global fue trabajado por varios autores: Strachan, Hew, "The First World War as a global war", en First World War Studies, 1, 1 (2010), pp. 3-14. https://doi. org/10.1080/19475021003621036; Sondhaus, Lawrence, World War I: The Global Revolution, New York, Cambridge University Press, 2011. https://doi.org/10.1017/CBO9780511973833; Gerwarth, Robert y ErezManela, "The Great War as a Global War: Imperial Conflict and the Reconfiguration of World Order, 1911-1923", en Diplomatic History, 38, 4 (2014), pp. 786-800. https://doi.org/10.1093/dh/dhu027; Janz, Oliver, "Einführung: Der Erste Weltkrieg in globaler Perspektive", en Geschichteund Gesellschaft, 40, 2 (2014), pp. 147-59. https://doi. org/10.13109/gege.2014.40.2.147; Bley, Helmut y Anorthe Kremers (eds.), The world during the First World War. Perceptions, experiences and consequences, Essen, Klartext, 2014; Lakitsch, Maximilian et al. (eds.), Bellicose Entanglements. 1914: The Great War as a Global War, Zurich, LitVerlag, 2015.

${ }^{9}$ Sin pretender exhaustividad sobre el tema ni reconstruir los debates historiográficos al respecto, recomendamos una serie de lecturas de referencia. Para cuestiones políticas y económicas, ver: Albert, Bill, South America and the First World War. The impact of the war on Brazil, Argentina, Peru and Chile, Cambridge, Cambridge University Press, 1988. https://doi.org/10.1017/CBO9780511529184; Belini, Claudio F., "El impacto de la Primera Guerra Mundial en la economía argentina", en Ciencia Hoy, 24, 139 (2014), pp. 21-26. «https://ri.conicet.gov.ar/ handle/11336/33316) ' [consultado el 27 de enero de 2021]; Dehne, Phillip, On the far western front. Britain's first world war in South America, Manchester, Manchester University Press, 2009; Díaz Araujo, Enrique, Yrigoyen y la guerra, Mendoza, Universidad Nacional de Cuyo, 1987; Rayes, Agustina, "Los destinos de las exportaciones y la neutralidad argentina durante la Primera Guerra Mundial", en Politica y cultura, 42 (2014), pp. 31-52. «https:// ri.conicet.gov.ar/handle/11336/10215» [consultado el 27 de enero de 2021]; Siepe, Raimundo y Montserrat Llairó, Yrigoyen, la Primera Guerra Mundial y las relaciones económicas, Buenos Aires, CEAL, 1992; Van der Karr, Jane, La Primera Guerra Mundial y la política económica argentina, Buenos Aires, Troquel, 1974; Weinmann, Ricardo, Argentina en la Primera Guerra Mundial: neutralidad, transición política y continuismo económico, Buenos Aires, Biblos, 1994; Dentro de lo social y cultural, ver: Compagnon, Olivier, América Latina y la Gran Guerra. El adiós a Europa (Argentina y Brasil, 1914-1939), Buenos Aires, Crítica, 2014; Compagnon, Olivier et al. (coords.), La Gran Guerra en América Latina. Una historia conectada, México D. F., CEMCA, 2018; Rinke, Stefan, Latin America and the First World War, Cambridge, Cambridge University Press, 2017. https:// doi.org/10.1017/9781316411735; Sánchez, Emiliano G., "Pasión de multitudes: la prensa y la opinión pública de Buenos Aires frente al estallido de la Gran Guerra", en Anuario IEHS, 33, 1 (2018), pp. 177-204. «https://ojs2.fch. unicen.edu.ar/ojs-3.1.0/index.php/anuario-ies/article/view/208» [consultado el 27 de enero de 2021]; Tato, María Inés, La Trinchera Austral. La sociedad argentina ante la Primera Guerra Mundial, Rosario, Prohistoria, 2017;
} 
la guerra en las Fuerzas Armadas ${ }^{10}$. Los trabajos son escasos, con ángulos que permanecen mayormente desatendidos por la historiografía. Uno en particular es la actividad asociativa de los clubes y centros de oficiales, durante aquellos años de contexto bélico. Dicho esto, es aquí donde intentaremos hacer nuestro aporte realizando un estudio introductorio sobre algunos de los impactos de la Primera Guerra Mundial en el círculo social que reunía a la mayor parte de la oficialidad de la Armada Argentina: el Centro Naval.

Para analizar esta cuestión, este artículo abordará dos aspectos fundamentales que hacen al funcionamiento del Centro, entre 1914 y 1918: primero, el rol y carácter de su labor social, es decir, los encuentros, reuniones y visitas que tuvieron lugar en sus instalaciones; segundo, la composición y el tipo de contenido que emitió su principal publicación, el Boletín del Centro Naval. Luego de esta doble tarea, será posible observar el grado y tipo de impacto que ejerció la Gran Guerra en aquella asociación.

Creemos que este estudio constituye una investigación importante y necesaria. Por un lado, porque acerca al lector a las repercusiones de la contienda en uno de los clubes militares más importantes del país, un centro de sociabilidad de los oficiales de la Armada Argentina, arma específica que ha sido descuidada historiográficamente. Por otro lado, porque muestra cómo los oficiales navales de un país neutral como la República Argentina, que no tuvo involucramiento directo en el conflicto y que se encontraba distante de los principales frentes de batalla, estuvieron igualmente atravesados por los hechos bélicos.

A modo de hipótesis, sostenemos que el Centro Naval no funcionó aislado de la situación internacional ni se mantuvo al margen de la conflagración. Por el contrario, operó como un mediador cultural y un nexo articulador, entre la Europa en guerra y la Argentina neutral, que supo transmitir a sus socios las últimas novedades de la contienda mediante trabajos y estudios elaborados por autores idóneos en temáticas navales ${ }^{11}$. Los oficiales argentinos demandaban informaciones sobre los hechos bélicos, a través de notas e informes, que, por su especificidad técnica, no se encontraban en la prensa masiva de la época. Esta última estaba más dedicada a la narración de combates y a la descripción esporádica de algunos elementos usados en la guerra, mientras que el Boletín del Centro Naval se ocupaba de analizar conceptos de táctica y

\footnotetext{
Dentro de lo diplomático, ver: Lanús, Juan A., Aquel Apogeo. Política internacional argentina, 1910-1939, Buenos Aires, Emecé, 2001; Pelosi, Hebe C., "La Primera Guerra Mundial. Relaciones internacionales franco-argentinas", en Temas de Historia Argentina y Americana, 4 (2004), pp. 155-184. «http://200.16.86.50/digital/9/revistas/th/ rth00029.pdf» [ [consultado el 27 de enero de 2021]; Solveira de Báez, Beatriz R., Argentina y la Primera Guerra Mundial según documentos del Archivo del Ministerio de Relaciones Exteriores y Culto, Córdoba, Centro de Estudios Históricos, 2004.

${ }^{10}$ Sobre los efectos de la guerra en el Ejército Argentino, ver: Dalla Fontana, Luis Esteban, "Los militares argentinos dijeron... La Gran Guerra en las publicaciones militares entre 1914 y 1918”, en Revista de la Escuela Superior de Guerra, 591 (2015), pp. 65-100. «http://cefadigital.edu.ar/handle/1847939/955» [consultado el 27 de enero de 2021]; Para el caso de la Armada, ver: Desiderato, Agustín Daniel, "La Primera Guerra Mundial y suinfluencia en la Armada Argentina, 1914-1927. Una aproximación", en Tato, María Inés et al. (coords.), Guerras del siglo XX. Experiencias y representaciones en perspectiva global, Rosario, Prohistoria, 2019, pp. 63-76.

${ }^{11}$ El concepto de "mediador cultural", ha sido trabajo por: D'Hulst, Lieven et al., "Towards a Multipolar Model of Cultural Mediators Within Multicultural Spaces. Cultural Mediators in Belgium, 1830-1945", en Revue Belge de Philologie et d'Histoire, 92 (2014), pp. 1255-1275. https://doi.org/10.3406/rbph.2014.8611
} 
estrategia, mecánica y operatoria de las nuevas naves y armamentos y los avances en materias como control de tiro, torpedos, reflectores y periscopios, entre otros ${ }^{12}$.

Las principales fuentes empleadas son los números del Boletín del Centro Naval que se emitieron durante los años de conflicto, además de algunos documentos de archivo y notas periodísticas, para poder contextualizar el material y una bibliografía de referencia, con artículos $\mathrm{y}$ libros, para fundamentar algunas de las ideas elaboradas en el texto ${ }^{13}$.

\section{La actividad asociativa del Centro Naval durante la Primera Guerra Mundial}

Al comienzo de la guerra, por un decreto del 5 de agosto de 1914, el presidente de la República Argentina, Victorino de La Plaza, declaró la "más estricta neutralidad". En adelante, se seguirían las reglas y procedimientos consignados en la "Convención referente a los derechos y deberes de las potencias neutrales", suscrita en La Haya, el 18 de octubre de 1907. Las distintas reparticiones de gobierno se ocuparían de impartir las instrucciones necesarias para el cumplimiento de esa neutralidad ${ }^{14}$.

A mediados de 1914, el Centro Naval ya había inaugurado su local y edificio definitivo en la Ciudad de Buenos Aires. En ese entonces, contaba con 625 socios, casi la totalidad de la oficialidad naval argentina ${ }^{15}$. De ahí que su entonces presidente, el capitán de navío Daniel Rojas Torres, se refiera al Centro como la "Casa de los Oficiales de la Armada"16. El número de socios aumentaría con el tiempo, llegando a 860 en mayo de $1918^{17}$.

\footnotetext{
${ }^{12}$ Esta es una de las razones por la cual las características de la prensa argentina durante la Gran Guerra no son extrapolables al caso del Boletín del Centro Naval: una publicación hecha por y para marinos, de tirada pequeña y contenido sumamente técnico y profesional, que transmitía informaciones no disponibles en los medios de la época a oficiales con preocupaciones propias de su profesión.

${ }^{13}$ Los boletines fueron consultados en la Biblioteca "Capitán Ratto", de la sede central del Centro Naval. Con esta referencia extiendo un agradecimiento al cordial personal del establecimiento.

${ }^{14}$ Ministerio de Relaciones Exteriores y Culto, Documentos y Actos de Gobierno relativos a la Guerra en Europa, Buenos Aires, Establecimiento gráfico Enrique L. Frigerio, 1919, pp. 13-14.

${ }^{15}$ Rojas Torres, Daniel, "Memoria Anual del Centro Naval 1914-1915", en Boletín del Centro Naval, 376/376 (1915), p. 73; Según un listado del 25 de febrero de 1914, el número de jefes y oficiales de la Armada era de aproximadamente 615 hombres ("Situación de los Señores jefes y Oficiales de la Armada el 25 de febrero de 1914", en Boletín del Centro Naval, 362/363 (1914), pp. 883-886); Contrariamente a algunas creencias instaladas acerca del Centro Naval, éste no se trató de una institución de elites, como sí lo eran el Círculo de Armas o el Jockey Club, ya que contemplaba la membresía de oficiales de diferente rango, desde guardiamarinas recién egresados hasta almirantes con varias décadas de servicio. De hecho, cabe advertir que el Centro había sido creado por jóvenes oficiales subalternos, a los que se sumaron profesores civiles de la Escuela Naval Militar, entre otros. Las más altas graduaciones de la Armada recibieron la iniciativa con desconfianza y la consideraron un acto de indisciplina y hasta una "rebelión juvenil" (González Lonzieme, Enrique, Historia del Centro... op. cit., pp. 1628); Sobre las elites, ver: Losada, Leandro, Historia de las elites en la Argentina: desde la conquista hasta el surgimiento del peronismo, Buenos Aires, Sudamericana, 2009.

${ }^{16}$ Rojas Torres, Daniel, "Memoria Anual del Centro... op. cit., p. 85; Durante la guerra, los presidentes del Centro Naval fueron Daniel Rojas Torres (1914-1915), Vicente E. Montes (1915-1916), Ismael F. Galíndez (1916-1917; 1917-1918) y Juan A. Martín (1918-1919).

${ }^{17}$ Galíndez, Ismael F., "Memoria del Centro Naval. Ejercicio 1917-1918", en Boletín del Centro Naval, 412 (1918), p. 109.
} 
Uno de los impactos de la Primera Guerra Mundial sobre el funcionamiento del Centro Naval puede observarse en su labor social, a través de los distintos encuentros y reuniones que tuvieron lugar en sus instalaciones. A modo de ejemplo, podrían mencionarse los organizados por la Cruz Roja Argentina, que buscaban recolectar fondos para las víctimas de la guerra.

... las Señoras del Comité de la Cruz Roja Nacional, dependiente de la Cruz Roja Internacional, dispusieron de algunos salones [...] por varios días, mientras reunían fondos de suscripción para las víctimas de la guerra actual. La Comisión Directiva ha considerado ceder nuestros salones a tan importantes asociaciones, por cuanto esas reuniones [...] son beneficiosas para el prestigio de esta Institución y de la Marina, aparte de los elevados móviles que persigue cada una de ellas. ${ }^{18}$

Asimismo, el Centro fue escenario de una dinámica y fructífera actividad de tipo asociativa, de carácter mayormente protocolar, que se relacionaba con la agenda de política exterior de la Argentina y el contexto bélico internacional del momento. Es el caso de la visita del almirante William Banks Caperton, comandante de la flota de Estados Unidos de Norteamérica encargada de patrullar aguas sudamericanas ${ }^{19}$.

El arribo de la escuadra de Caperton respondía a un ejercicio de diplomacia, para declarar intereses y reafirmar lazos de amistad en la región ${ }^{20}$. Buscaba aumentar la influencia estadounidense en la Argentina, aunque también colocaba a sus autoridades frente a un inconveniente: la permanencia de barcos de una nación beligerante en un puerto neutral, por más de 24 horas, significaba una violación de la Convención de la Haya ${ }^{21}$. A pesar de ello, se decidió recibir "en aguas nacionales a la escuadra norteamericana en calidad de amiga" ${ }^{22}$.Un amplio público presenció su arribo al puerto de Buenos Aires ${ }^{23}$.

Después de una audiencia presidencial, el almirante Caperton y sus oficiales fueron invitados a un banquete en el Centro $\mathrm{Naval}^{24}$. Entre los asistentes se encontraba Frederick J. Stimson, embajador de Estados Unidos en Argentina, y figuras relevantes de la Armada Argentina como el almirante Rafael Blanco, el vicealmirante Manuel Domecq García y el

\footnotetext{
${ }^{18}$ Rojas Torres, Daniel, "Memoria Anual del Centro... op. cit., p. 82.

19 "Viene con la escuadra norteamericana, a la que daremos pruebas de amistad con la mejor gana, sin que nos lo impida la neutralidad" (Fray Mocho, 29 junio de 1917, p. 19); "La bandera norteamericana desplegada sobre el Atlántico para asegurar la libre navegación. El almirante Caperton, jefe de la escuadra que actualmente visita esta capital" (Mundo Argentino, 25 de julio de 1917, p. 1).

${ }^{20}$ Widen, J. J., "Naval Diplomacy. A Theoretical Approach", en Diplomacy \& Statecraft, 22, 4 (2011), p. 723. https://doi.org/10.1080/09592296.2011.625830; “Además de las patrullas mantenidas en cooperación con los ingleses y franceses, en este lado del Atlántico, la Escuadra de [...] Caperton, ha hecho visitas de cortesía a los países de Sud América..." ("Crónica extranjera. Visitas de cortesía", en Boletín del Centro Naval, 409/411 (1918), p. 652).

${ }^{21}$ Weinmann, Ricardo, Argentina en la Primera ... op. cit. p. 126.

${ }^{22}$ Ministerio de Relaciones Exteriores y Culto, Documentos y Actos... op. cit., p. 106.

${ }^{23}$ Stimson, Frederic J., My United States, New York-London, Charles Scribner's Sons, 1931, pp. $391-392$.

24 "Visita de la escuadra norteamericana a la Argentina", en Mundo Argentino, 1 de agosto de 1917; "Agasajos al Almirante Caperton. Visita al Centro Naval y Militar”, en La Prensa, 22 de enero de 1919.
} 
contraalmirante Eduardo $\mathrm{O}^{\prime} \mathrm{Connor}^{25}$. Varios discursos se pronunciaron durante aquella jornada, que fue calificada como una "fiesta de confraternidad americana"26.

Caperton felicitó a la "distinguida concurrencia" que se encontraba allí reunida. Señaló que "los acontecimientos" que habían "conmovido al mundo" y llevado a Estados Unidos a tomar la "defensa de la causa de la democracia", no podrían sino "haber excitado los corazones y el alma de los hijos de San Martín" y propuso un brindis "por la Argentina y su armada"27. La escuadra estadounidense permaneció en Buenos Aires durante cinco días y, pese a todo, el gobierno argentino sostuvo su neutralidad ${ }^{28}$.

Para estrechar aún más los lazos económicos bilaterales y contrarrestar la influencia estadounidense, a la República Argentina llegaría luego una delegación comercial británica, al mando de sir Maurice de Bunsen, en junio de $1918^{29}$. La comitiva arribó a bordo del crucero Newcastle, que aprovechó la estadía para efectuar "ciertas reparaciones"30. Y como ocurrió con la escuadra de Caperton, los británicos también fueron recibidos en los salones Centro Naval, siendo agasajados por sus autoridades y $\operatorname{socios}^{31}$.

Además de las visitas diplomáticas, las instalaciones del Centro Naval también fueron el lugar donde la oficialidad de la Armada solía dictar charlas y conferencias, sobre temas de interés. Esta práctica fue común, porque se relacionaba con uno de los objetivos y cometidos de la asociación; sin embargo, la Primera Guerra Mundial monopolizó los tópicos de las disertaciones. Entre 1914 y 1918, se debatía sobre las tácticas, estrategias, unidades y medios empleados por los beligerantes. Ejemplo de esto fueron las exposiciones del teniente de navío Melchor Z. Escola, sobre los tipos, medios y elementos aéreos empleados en la contienda, o la conferencia sobre submarinos del capitán de fragata Pedro S. Casal ${ }^{32}$. Ambas fueron muy bien recibidas por el público, que parecía tener curiosidad por el funcionamiento de las nuevas armas.

El capitán de fragata, señor Pedro casal, en el momento de explanar su interesante conferencia sobre todo cuanto se refiere a la construcción de submarinos; los diversos tipos, actualmente en uso, y los diferentes sistemas

\footnotetext{
25 "La visita de la Escuadra Norteamericana", en Caras y Caretas, 4 de agosto de 1917.

26 "Demostración al Almirante Caperton en el Centro Naval", en Boletín del Centro Naval, 403/405 (1917), p. 275.

${ }^{27}$ Ibidem, p. 276.

${ }^{28}$ Weinmann, Ricardo, Argentina en la Primera ... op. cit., p. 128; Estados Unidos se mantuvo neutral durante los primeros años de guerra. Sin embargo, los incidentes diplomáticos producidos por la campaña submarina alemana y la intercepción del Telegrama Zimmerman, que reveló un complot alemán para ayudar a México a recuperar Texas, Nuevo México y Arizona, si atacaba a Estados Unidos, llevaron a su involucramiento en ayuda del bando aliado, en abril de 1917.

${ }^{29}$ Weinmann, Ricardo, Argentina en la Primera ... op. cit., p. 139.

${ }^{30}$ Ministerio de Relaciones Exteriores y Culto, Documentos y Actos... op. cit., p. 130; "Llegada de la embajada británica", en Caras y Caretas, 8 de junio de 1918; "Sir Maurice de Bunsen. Llegada a nuestra capital de la embajada extraordinaria de la Gran Bretaña", en El Hogar, 7 de junio de 1918.

31 "El banquete en el Centro Naval", en Mundo Argentino, 12 de junio de 1918; "El banquete realizado en honor de los marinos ingleses en el 'Centro Naval'”, en El Hogar, 14 de junio de 1918.

32 “Crónica Nacional. Nota”, en Boletín del Centro Naval, 397/399 (1917), p. 535; "Crónica Nacional. Submarinos Modernos. Conferencia dada por el capitán de fragata Pedro S. Casal”, en Boletín del Centro Naval, $394 / 396$ (1916), pp. 449-452.
} 
de tubos y lanzamiento de torpedos. El conferenciante fue muy aplaudido y felicitado. ${ }^{33}$

Con sus reuniones, visitas y conferencias, toda la actividad social desempeñada en los salones del Centro Naval, entre 1914 y 1918, se transcribía y publicaba en las páginas de un boletín: el Boletín del Centro Naval. A él nos dedicaremos en el apartado siguiente.

\section{Un boletín para los oficiales de la Armada}

Durante el desarrollo de la Gran Guerra, la periodicidad del Boletín del Centro Naval nunca se interrumpió con casi cincuenta números lanzados entre mediados de 1914 y fines de 1918. Al principio la publicación fue bimestral, pero pasó a ser trimestral luego del incendio de la imprenta del Ministerio de Marina ${ }^{34}$.Además de ser consumidos por los socios, cierta cantidad de ejemplares se canjeaban con bibliotecas nacionales y asociaciones en el exterior ${ }^{35}$. Esta circulación recíproca y sostenida le permitió al Centro Naval hacerse de un diverso y variopinto número de publicaciones especializadas de varias naciones, que durante el conflicto incluyó a las potencias beligerantes, como, por ejemplo: Revue Maritime, de Francia; Shipping Illustrated, de Gran Bretaña, Revista Marittima, de Italia; United States Naval Institute y Journal of the American Society of Naval Engineers, de Estados Unidos; Morskoy Sbornik, de Rusia; Marine Rundschau, de Alemania; Mitteilungenausdem Gebiete des Seewesens, de Austria ${ }^{36}$.

Para su posterior consulta, los números recibidos se depositaban en un repositorio propio, la Biblioteca Nacional de Marina, que había sido creada el 23 de diciembre de 1913, por decreto de la Armada n. ${ }^{\circ}$ 6191, para reunir en un solo local todos los libros y documentos de las distintas reparticiones de la Marina además de las donaciones que realizaban los socios del Centro $^{37}$. Gracias a sus más de 3.000 volúmenes, se podía acceder a diverso material de índole nacional e internacional y tomar contacto con "la mejor información sobre asuntos de interés profesional" 38 .

\footnotetext{
33 "En el Centro Naval", en Caras y Caretas, 6 de enero de 1917.

34 "Memoria anual del Centro... op. cit., p. 77; "El gran incendio de la Intendencia de Marina", en Mundo Argentino, 14 de octubre de 1914; El Ministerio de Marina fue creado bajo iniciativa del presidente de la Nación Julio Argentino Roca, el 11 de octubre de 1898. Tenía a su cargo todo lo relativo a la Armada, la marina mercante, la navegación y la industria naval. Durante los años de la guerra los ministros fueron el vicealmirante Juan Pablo Sáenz Valiente (1910-1916) y el ingeniero Federico Álvarez de Toledo (1916-1919).

35 "Memoria del Centro Naval. Ejercicio 1917-1918", en Boletín del Centro Naval, 412 (1915), p. 107.

36 “Publicaciones recibida en canje. Noviembre y diciembre 1915", en Boletín del Centro Naval, $382 / 383$ (1915), pp. 563-565.

${ }^{37}$ Rojas Torres, Daniel, "Memoria Anual de la Comisión... op. cit., pp. 59-60, 62; Domínguez, Ercilio, Colección de Leyes y Decretos Militares concernientes al Ejército y Armada de la República Argentina 1810-1916, tomo 8, Buenos Aires, Talleres Gráficos-Arsenal Principal de Guerra, 1916, p. 53.

38 "Memoria del Centro Naval 1915-1916", en Boletín del Centro Naval, 388/390 (1916), p. 117.
} 
Entre 1914 y 1918, el contenido de boletín se dividió en varias secciones. Por una parte, transmitió noticias, tanto locales como foráneas, a través de periódicos como La Nación y La Prensa, de Argentina, Daily Telegraph, de Reino Unido, o Daily Chronicle, Daily Newsy Daily Graphic, de Estados Unidos, entre otros ${ }^{39}$. Con ello se buscaba mantener informados a los lectores sobre distintos acontecimientos de relevancia, sobre todo si se relacionaban con cuestiones navales y marítimas que tocaban a la Argentina durante la guerra, como el apresamiento del vapor Presidente Mitre, por parte de autoridades británicas, a fines de 1915, o los hundimientos de los buques Monte Protegido, Oriana y Toro, por submarinos alemanes, entre abril y junio de $1917^{40}$.

Por otra parte, también presentó artículos especializados, escritos por los propios socios, con opiniones, reflexiones y debates sobre los combates entre escuadras, las características de las unidades navales más modernas y las tácticas y estrategias empleadas por los beligerantes. Es el caso de Los cruceros auxiliares. Su evolución ante el derecho internacional, de Benjamín Villegas Basavilbaso, alférez de navío retirado, que por entonces se desempeñaba como profesor de historia en la Escuela Naval Militar y director del Boletín del Centro $\mathrm{Naval}^{41}$. Su escrito respondía a la práctica, por parte de varias Armadas combatientes, de emplear cruceros auxiliares, es decir, buques mercantes o de pasajeros a los que se dotaba de armamento para colaborar con las operaciones de guerra.

\begin{abstract}
La guerra europea nos ha demostrado la insuperable eficacia de los cruceros auxiliares. Es innecesario recordar la perturbación sufrida por el comercio inglés durante los primeros meses de la guerra. La presencia de un reducido número de buques armados fue suficiente para debilitar el sea power británico, y ya sabemos qué significa en la economía de esa gran nación la pérdida aunque fuera por breve tiempo- de sus varias veces secular dominación marítima. $^{42}$
\end{abstract}

Las apreciaciones de Basavilbaso fueron producto no solo de sus conocimientos navales, sino también de su formación como abogado. Había pedido el retiro de la Armada en 1911 para

\footnotetext{
39 "Crónica Extranjera. Diario de los acontecimientos marítimos de la guerra europea”, en Boletín del Centro Naval, 380/381 (1915), pp. 400-433; "Crónica Extranjera. Operaciones Marítimas. 15 de febrero al 15 de abril", en Boletín del Centro Naval, 386/387 (1916), pp. 913-918; “Crónica extranjera. La guerra submarina”, en Boletín del Centro Naval, $397 / 399$ (1917), pp. 556-597; “Crónica extranjera. La guerra marítima”, en Boletín del Centro Naval, 403/405 (1917), pp. 306-311.

40 “Crónica Nacional. Apresamiento del Presidente Mitre”, en Boletín del Centro Naval, 384/385 (1916), pp. 671685; "Crónica Nacional. Hundimiento del velero argentino 'Monte Protegido"”, en Boletín del Centro Naval, 397/399 (1917), pp. 549-554; “Crónica Nacional. Documentos oficiales relativos al hundimiento del buque argentino "Toro", en Boletín del Centro Naval, 403/405 (1917), pp. 268-274.

${ }_{41}$ Villegas Basavilbaso, Benjamín, "Los cruceros auxiliares. Su evolución ante el derecho internacional", en Boletín del Centro Naval, 384/385 (1916), pp. 637-670; La Escuela Naval Militar era el centro educativo donde se formaban los cuadros superiores de la Armada. Durante los años de guerra funcionó en Río Santiago (Provincia de Buenos Aires), ocupando un edificio en el Arsenal del Río de La Plata.

${ }^{42}$ Villegas Basavilbaso, Benjamín, "Los cruceros auxiliares... op. cit., p. 669.
} 
estudiar Derecho en la Universidad de Buenos Aires, casa de estudios de la que se graduaría años más tarde ${ }^{43}$.

Otros ejemplos de artículos referidos, directa o indirectamente, con la guerra fueron Operaciones combinadas del Ejército y la Armada, del capitán de fragata Gabriel Albarracín, Sanidad naval de Combate, del cirujano principal César Rollino, Polígonos de torpedos, del capitán de fragata Pedro S. Casal, o Importancia económica y política de las instituciones militares, de Benjamín Villegas Basavilbaso, entre otros ${ }^{44}$.

Por su parte, los autores extranjeros también encontraron espacio en las páginas del boletín, para escribir sobre la guerra. Trabajos como El Papel de la Doctrina en la Guerra Naval, de Dudley W. Knox, o Cañón versus coraza, de Bernard Walker, se traducían al español por socios con conocimientos en idiomas, tales como Mauricio King, en ese entonces profesor de inglés en la Escuela Naval Militar ${ }^{45}$. Finalmente, el boletín solía difundir partes e informes de servicios navales extranjeros, que previamente habían sido publicados en revistas internacionales. Es el caso de Combates navales de Santa María y de las Malvinas, del contraalmirante alemán Kalau Von Hofe ${ }^{46}$.

\section{La mediación cultural}

Luego de lo expuesto en los apartados anteriores, es posible observar que, por la actividad asociativa y el contenido de sus boletines, el Centro Naval no funcionó aislado de la situación internacional ni se mantuvo al margen de los acontecimientos. Por el contrario, operó como un verdadero mediador cultural y como un nexo articulador entre la Europa en guerra y la Argentina neutral ${ }^{47}$. Esto último es importante porque vuelve a reafirmar la idea de autores como Olivier Compagnon y Pierre Purseigle, sobre la necesidad de incluir múltiples vectores — personas y bienes culturales - para dar cuenta de la complejidad que adquirió la Primera Guerra Mundial como fenómeno global. Solo así sería posible superarlos espacios convencionales de las

\footnotetext{
43 “Doctor Benjamín Villegas Basavilbaso", en El Hogar, 16 de diciembre de 1949.

${ }^{44}$ Albarracín, Gabriel, "Operaciones combinadas del Ejército y la Armada”, en Boletín del Centro Naval,372/373 (1915), pp. 612-655; Rollino, César, "Sanidad naval de combate”, en Boletín del Centro Naval,380/381 (1915), pp. 375-378; Casal, Pedro S., "Polígonos para torpedos", en Boletín del Centro Naval,394/396 (1916), pp. 405-410; Villegas Basavilbaso, Benjamín, "Importancia económica y política de las instituciones militares", en Boletín del Centro Naval, $397 / 399$ (1917), pp. 481-491.

${ }^{45}$ Knox, Dudley W., "El Papel de la Doctrina en la Guerra Naval”, en Boletín del Centro Naval, $388 / 390$ (1916), pp. 11-54; Walker, Bernard J., "Cañón versus coraza. ¿Habrá que modificar la distribución de la coraza en vista del ataque a grandes distancias con cañones de grueso calibre?", en Boletín del Centro Naval, 400/402 (1917), pp. 23-29.

${ }^{46}$ VonHofe, Kalau, “Combates navales de Santa María y de las Malvinas”, en Boletín del Centro Naval, $384 / 385$ (1916), pp. 568-583.

${ }^{47}$ Tato, María Inés, La Trinchera ... op. cit., p. 13; D’Hulst, Lieven et al., “Towards... op. cit., pp. 1255-1275.
} 
operaciones bélicas, para alcanzar aquellas geografías distantes y neutrales de los principales frentes de batalla ${ }^{48}$.

Pero ¿por qué el Centro Naval desempeñó ese rol mediador? Después de todo, se trataba de una asociación de oficiales navales de un país neutral, que no se involucró en la conflagración. ¿Por qué existió interés en mediar culturalmente los hechos de un conflicto del cual no se participó? Reflexionemos sobre algunas cuestiones para elaborar posibles respuestas.

En primer lugar, que el Centro Naval haya sido sede de diversos encuentros y reuniones de Armadas y Marinas extranjeras no debería sorprendernos, pues este era uno de sus principios fundacionales. Ser el lugar de recepción de los "marinos de naciones extranjeras", era una costumbre y una cuestión de "hospitalidad", decía el presidente del Centro, el capitán de navío Ismael Galíndez ${ }^{49}$. En segundo lugar, el Boletín del Centro Naval decidió reproducir datos y noticias sobre la guerra, porque su objetivo era ese: difundir todo aquello relacionado con "las innovaciones modernas en el arte de la guerra marítima" ${ }^{50}$. Sin embargo, estas cuestiones cobraron especial relevancia entre 1914 y 1918, por una serie de motivos que trabajaremos a continuación.

La Primera Guerra Mundial se trató de un acontecimiento que expuso a millones de personas a nuevas experiencias, cuando los beligerantes transformaron el espacio marítimo en una zona de lucha por el control de materiales y alimentos ${ }^{51}$. Se emplearon nuevas tácticas y estrategias, además de modernos desarrollos tecnológicos, que significaron un corte profundo en la concepción y práctica del combate naval, como se lo conocía hasta entonces ${ }^{52}$. Todo ello impactó en los socios del Centro Naval, como el capitán de fragata Pedro Casal, quien afirmaba que "la guerra actual" era "la más grande y la más sangrienta" conocida hasta entonces ${ }^{53}$. Asimismo, sobre los sucesos bélicos que observaba, el capitán de fragata retirado Esteban de Loqui decía:

\footnotetext{
Vemos realizar actualmente y mucho más que lo hubiéramos creído los sueños de nuestra juventud con respecto a la lucha naval y terrestre. Todo lo escrito admirablemente por el ameno e ilustre Julio Verne ha dejado de ser ficción y el hombre ahora emplea en combates sanguinarios todas las conquistas científicas que ha hecho en el mar, en tierra y en el aire. ${ }^{54}$
}

\footnotetext{
${ }^{48}$ Compagnon, Olivier y Purseigle Pierre, "Geographies of Mobilization and Territories of Belligerenceduring the First World War", en Annales. Histoire, Sciences Sociales, 71, 1 (2016), pp. 43-44. https://doi.org/10.1017/ S2398568217000024

49 "Memoria del Centro... op. cit., p. 118.

${ }^{50}$ Albarracín, Santiago J., "Algunas palabras... op. cit., p. 8.

${ }^{51}$ Winter, Jay, Remembering War: The Great War Between Memory and History in the Twentieth Century, New Haven, Yale University Press, 2006, pp. 17-51; Horne, John (ed.), A Companion to World War I, Chichester, WileyBlackwell, 2012, p. xviii.

${ }^{52}$ Howard, Michael, La guerra en la historia europea, México D.F., Fondo de Cultura Económica, 1983, pp. 219222; Hobsbawm, Eric, Historia del Siglo XX, Buenos Aires, Crítica, 2012, p. 29.

${ }^{53}$ Casal, Pedro S., "Influencia del dominio marítimo", en Boletín del Centro Naval, 413 (1918), p. 224.

${ }^{54}$ De Loqui, Esteban, “Carta al Director”, en Boletín del Centro Naval, 378/379 (1915), p. 291.
} 
El factor tecnológico desarrollado durante la contienda superó las expectativas de los oficiales argentinos. Se habían producido grandes cambios en las Armadas y en el entramado social que las componía. Las fuerzas navales se militarizaron gradualmente mucho más que en siglos anteriores y dependían cada vez más del uso de tecnologías que cambiaban continuamente. Por ello, se comenzó a precisar de un tipo específico de oficial, con una capacitación más avanzada y una educación más amplia, para operar el equipamiento de los buques de guerra ${ }^{55}$. El desarrollo militar iniciado antes de 1914 se acentuó durante los cuatro años y medio de guerra. Su sofisticación llevó a que sea requerida una especialización cada vez mayor por parte del soldado o del marino, quienes además de combatientes pasaban a ser técnicos especializados ${ }^{56}$.

La acelerada modernización de los medios navales impactó en el desarrollo de la lucha en el mar. A diferencia de lo que ocurría en siglos previos, los enfrentamientos pasaron a ser distantes e impersonales por la utilización de cañones de largo alcance, torpedos autopropulsados y aeronaves ${ }^{57}$. Para Esteban de Loqui, la nueva conflagración que se desarrollaba era "científica".

\begin{abstract}
... esta contienda que ante todo es una guerra científica; son los mismos hombres de hace cien años que pelean también con la misma energía y coraje, pero con maquinaría de incomparable valor con respecto a destrucción; el heroísmo de los soldados y marinos ha crecido en razón directa de las numerosas bajas que producen las terribles armas modernas. El valor personal, nada vale en estos días si no es combinado con la tenacidad unida a la instrucción técnica del combatiente. ${ }^{58}$
\end{abstract}

Por aquella transformación de la guerra, los cuadros de la Armada y los socios del Centro Naval entendieron que, en lo sucesivo, deberían mantenerse actualizados si pretendían continuar cumpliendo con su función principal: defender los espacios marítimos de la República Argentina. No obstante, tomar contacto con ese tipo de información no resultaba fácil en el contexto bélico imperante.

Desde el principio, las autoridades de la Armada habían manifestado un sólido interés por observar el desarrollo de las operaciones pero de primera mano, es decir, incorporando oficiales en las escuadras beligerantes. En ese sentido, se iniciaron gestiones para admitir oficiales en las fuerzas navales británicas, francesas y alemanas ${ }^{59}$. Sin embargo, Francia no accedió al pedido,

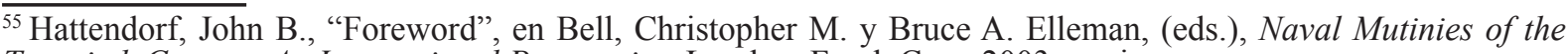
Twentieth Century. An International Perspective, London, Frank Cass, 2003, p. xiv.

${ }^{56}$ Audoin-Rouzeau, Stéphane, "Weapons", en Ute, Daniel et al. (eds.), 1914-1918-online. International Encyclopedia of the First World War, Berlin, Freie Universität Berlin, 2014. [en línea] «https://encyclopedia.19141918-online.net/article/weapons»' [consultado el 22 de enero de 2021].

${ }^{57}$ Reeve, John, "Introduction: ananatomy of the face of naval battle", en Reeve, John y David Stevens (eds.), The Face of Naval Battle: The Human Experience of Modern War at Sea, Crow's Nest, Allen \& Unwin, 2003, pp. 1112.

${ }^{58}$ DeLoqui, Esteban, “Carta al Director”, en Boletín del Centro Naval, 378/379 (1915), p. 290.

${ }^{59}$ Argentina, Buenos Aires, Archivo del Ministerio de Relaciones Exteriores y Culto (en adelante, AMREC), Primera Guerra Mundial, AH/0044/25, "Telegrama del Ministro de Marina, Juan Pablo Sáenz Valiente, al ministro de Relaciones Exteriores, José Luis Murature", Buenos Aires, 18 de agosto de 1914, foja 1.
} 
argumentando que este solo podía ser otorgado a los miembros de las flotas aliadas" ${ }^{90}$. De igual modo se negó Gran Bretaña, señalando que no sería posible "incorporar oficiales de marina de ningún país neutral a las operaciones de guerra" de su escuadra ${ }^{61}$. Por su parte, Alemania tampoco aceptó el pedido ${ }^{62}$.

En ese contexto, los oficiales argentinos quedaban frente a un escenario complejo, con pocas posibilidades de tomar contacto con el conflicto. En última instancia, podrían conformarse con la información facilitada por la prensa ${ }^{63}$. Sin embargo, existían limitaciones. En primer lugar, como señala John Reeve, la propia característica de la guerra marítima hacía difícil su cobertura por parte de los medios de comunicación. Los enfrentamientos solían estar naturalmente alejados de las poblaciones locales y de la mirada de la gente en tierra. Se producían de manera inesperada y terminaban súbitamente, con pocos sobrevivientes que den cuenta del acontecimiento ${ }^{64}$

En segundo lugar, como señala la cita a continuación, si la prensa cubría algunos enfrentamientos, lo hacía de forma mayormente narrativa. No difundía los estudios y elaboraciones técnicas que interesaban a los marinos argentinos.

\begin{abstract}
Fuera de la narración oficial y del telégrafo, hechos relacionados con la acción de las flotas beligerantes son poco abundantes y por lo general aislados, que impiden al crítico sacar consecuencias o resultantes que marquen el progreso naval de la guerra o la superioridad de tal o cual arma empleada en la contienda. Las naciones en guerra usan su actividad en diferentes esferas $[\ldots]$ y el espíritu inventivo con respecto a elementos de destrucción tiende cada día a desarrollarse de una manera sorprendente, sea en tierra sea en el mar. ${ }^{65}$
\end{abstract}

En consecuencia, la necesidad de información especializada fue cubierta por el Centro Naval, que se convirtió en un interlocutor válido de las demandas de la oficialidad argentina. Supo mediar los acontecimientos de la contienda y dar a conocer un "análisis razonado de los hechos" con "anheladas pruebas de la eficiencia y valor de combate" de las modernas armas utilizadas $^{66}$. De ahí que el vicealmirante Juan Pablo Sáenz Valiente se refiera al Centro Naval como el "representante del personal" de la Armada ${ }^{67}$. Tanto sus autoridades, como gran parte

\footnotetext{
${ }^{60}$ AMREC, Primera Guerra Mundial, AH/0044/17, “Telegrama del Ministro argentino al Ministro de Relaciones Exteriores, José Luis Murature", Burdeos, 21 de noviembre de 1914, foja 3.

${ }^{61}$ AMREC, AH/0044/19, "Telegrama cifrado n 674 del Ministro argentino al Ministro de Relaciones Exteriores, José Luis Murature”, Londres, 19 de septiembre de 1914, foja 3.

${ }^{62}$ AMREC, AH/0065/16; "Telegrama cifrado del Ministro argentino al Ministro de Relaciones Exteriores, José Luis Murature", 4 de septiembre de 1914, foja 32; AMREC, AH/0044/24, "Telegrama cifrado del Ministro argentino al Ministro de Relaciones Exteriores, José Luis Murature", Buenos Aires, 11 de septiembre de 1914, foja 1.

63 "En tiempos en los que la prensa constituía el medio de comunicación de masas por antonomasia, los diarios y las revistas se erigieron en referentes insoslayables de una sociedad inquieta por los sucesos europeos" (Tato, María Inés, La Trinchera... op. cit., p. 37).

${ }^{64}$ Reeve, John, "Introduction... op. cit., p. 7.

${ }^{65}$ De Loqui, Esteban, "Algunas consideraciones sobre la guerra europea", en Boletín del Centro Naval, 406/408 (1917), pp. 481-487.

66 "El conflicto europeo", en Boletín del Centro Naval, 366/367 (1914), pp. 275-277.

${ }^{67}$ “Crónica Nacional. Recepción en honor de los marinos extranjeros - 11 de Julio", en Boletín del Centro Naval, $388 / 390$ (1916), p. 126
} 
de sus socios, pertenecían a los oficiales que se habían formado bajo un mismo modelo e instrucción educativa, la Escuela Naval Militar, lo que daba homogeneidad a sus intereses.

Durante las primeras décadas del siglo xx, la Armada Argentina era ya una fuerza cohesiva e "institucionalizada", por el tipo de valores que recibían sus cuadros más jóvenes, en su etapa de formación. Desde que aprobaban su examen de admisión, los cadetes aprendían un código ético que exigía una estricta lealtad para con el arma y bajo ese marco transcurría buena parte de su vida profesional. Los oficiales tendían a encerrarse en un "endogrupo", con una existencia aislada del resto de la sociedad, tanto a bordo de los buques como en las poblaciones cercanas a sus bases navales. Estas características robustecían la lealtad del marino hacia la Armada y derivaron en una uniformidad de pensamiento y comportamiento en contextos de crisis ${ }^{68}$. Entre 1914 y 1918, ese contexto de crisis bien podría haber sido la Gran Guerra.

Los oficiales argentinos deseaban estar al tanto de las últimas tecnologías empleadas en el frente marítimo. El Centro Naval cumplió esa labor informativa, funcionando como un mediador, que hizo posible ciertos significados sociales y culturales, aunque con alteraciones ${ }^{69}$. Transformó y resignificó la experiencia bélica, según las propias apreciaciones que los marinos hacían de ella, con los debates y discusiones que propiciaban las lecturas y conferencias relacionadas con los temas "profesionales" o "científicos" que difundía el Centro ${ }^{70}$.

\section{Conclusión}

La documentación analizada a lo largo de estas páginas permite observar que, durante los agitados años de la Primera Guerra Mundial, el Centro Naval funcionó como algo más que un simple "club social" de oficiales de la Armada Argentina. También operó como un mediador cultural, es decir, un nexo y agente articulador que le transmitió a sus miembros las últimas novedades de la contienda mediante trabajos y estudios elaborados por autores idóneos en temáticas navales.

A pesar de no tener observadores en las escuadras beligerantes y de la estricta neutralidad defendida por el gobierno argentino, la oficialidad de la Armada no permaneció pasiva ante la Gran Guerra. Por el contrario, intentó mantenerse activa, recolectando información sobre el desempeño de las fuerzas combatientes y sus tácticas, estrategias, medios y armas. Satisfacer aquella necesidad fue uno de los roles que cumplió el Centro Naval, acercando un tipo de

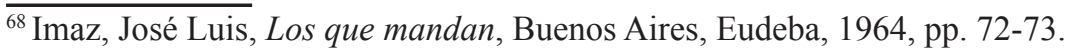

${ }^{69}$ Dentro de las categorías de mediación, François Debrix hace referencia a aquella que funciona como un "ritual de transformación", esto es, una que no deja inalteradas las posiciones de objeto y sujeto (Debrix, François, "Introduction: Rituals of Mediation", en François, Debrix y Cynthia Weber, Rituals of Mediation: International Politics and Social Meaning, Minneapolis-London, University of Minnesota Press, 2003, pp. XXI-XLII).

70 "Memoria del Centro... op. cit., p. 117.
} 
contenido diferente al que los oficiales argentinos podía encontrar en revistas y periódicos masivos.

En conclusión, detectar cómo la Primera Guerra Mundial impactó en el funcionamiento del Centro Naval no solo señala el alcance transnacional que consiguió el conflicto, sino su permeabilidad en espacios poco explorados, como es el caso de una asociación constituida por oficiales de la Armada Argentina, país que no se involucró directamente en la contienda. Por razones como estas, las asociaciones y clubes militares precisan ser repensados bajo preguntas de trabajo que los incluyan en un marco más amplio, que permitan un acercamiento al perfil sociocultural de los profesionales castrenses en contextos de crisis. 